\title{
VERY WEAK SOLUTIONS OF LINEAR ELLIPTIC PDES WITH SINGULAR DATA AND IRREGULAR COEFFICIENTS
}

\author{
JOCHEN MERKER
}

Abstract. In this article it is shown that linear elliptic PDEs admit very weak solutions for rather singular data - like non-integrable right hand sides or singular Neumann boundary conditions not only in case of continuous coefficients, but even for general bounded measurable coefficients. This is rather astonishing, as under such weak assumptions on the coefficients generally strong solutions do not exist, thus the duality between very weak solutions and strong solutions seems to indicate that very weak solutions do not exist either. We circumvent this problem by using an appropriate functional analytic setting and particularly Hölder continuity of weak solutions established by de Giorgi - Nash - Moser to obtain existence of very weak solutions to singular data for irregular coefficients.

Mathematics subject classification (2010): 35J25, 35D99.

Keywords and phrases: elliptic PDE, very weak solution; singular data, measurable coefficients.

\section{REFERENCES}

[1] F. Abergel, J.-M. Rakotoson, Gradient blow-up in Zygmund spaces for the very weak solution of a linear elliptic equation, DCDS Series A 33 (2013), 1809-1818.

[2] H. BRÉZIS, X. CABRÉ, Some simple nonlinear PDE's without solutions, Boll. Unione Mat. Ital. 1-B (1998), 223-262.

[3] H. Brézis, T. Cazenave, Y. Martel, A. Ramiandrisoa, Blow-up for $u_{t}-\Delta u=g(u)$ revisited, Adv. Differ. Equ. 1 (1996), 73-90.

[4] E. De Giorgi, Sulla differenziabilità e l'analiticità delle estremali degli integrali multipli regolari, Mem. Accad. Sci. Torino. Cl. Sci. Fis. Mat. Nat. 3, 3 (1957), 25-43.

[5] J.I. DíAz, J.-M. RAKotoson, On the differentiability of very weak solutions with right-hand side data integrable with respect to the distance to the boundary, J. Funct. Anal. 257 (2009), 807-831.

[6] J.I. DíAZ, J.-M. RAKOTOSON, On very weak solutions of semi-linear elliptic equations in the framework of weighted spaces with respect to the distance to the boundary, DCDS Series A 27 (2010), 1037-1958.

[7] K. Disser, H.-C. KAISER, J. RehBERG, Optimal Sobolev regularity for linear second-order divergence elliptic operators occurring in real-world problems, WIAS preprint 1977 (2014).

[8] D. Gilbarg And N. TRudinger, Elliptic partial differential equations of second order, Springer, 2001.

[9] J.A. GRIePENTROG, L. ReCKe, Linear elliptic boundary value problems with non-smooth data: Normal solvability on Sobolev-Campanato spaces, WIAS preprint 446 (1998).

[10] K. GRÖGER, A $W^{1, p}$-estimate for solutions to mixed boundary value problems for second order elliptic differential equations, Math. Ann. 283 (1989), 679-687.

[11] H. Kozono, T. Yanagisawa, Generalized Lax-Milgram theorem in Banach spaces and its application to the elliptic system of boundary value problems, Manuscripta Math. 141 (2013), 637-662.

[12] S. LEONARDI, Remarks on the regularity of solutions of elliptic systems, in Applied Nonlinear Analysis, A. Sequeira, H.B. da Veiga, J.H. Videman (Eds), Kluwer Academic Publishers, New York, 2002, 325-344.

[13] P.J. McKenna, W. Reichel, A priori bounds for semilinear equations and a new class of critical exponents for Lipschitz domains, J. Funct. Anal. 244 (2007), 220-246. 
[14] J. Merker And J.-M. Rakotoson, Very weak solutions of Poisson's equation with singular data under Neumann boundary conditions, Calc. Var. PDE 46, 1 (2015), 157-159.

[15] J. MOSER, A new proof of De Giorgi's theorem concerning the regularity problem for elliptic diffrential equations, Comm. Pure Appl. Math. 13 (1960), 457-468.

[16] J. NASH, Continuity of solutions of parabolic and elliptic equations, Amer. J. Math. 80 (1958), $931-$ 954.

[17] J.-M. Rakotoson, Linear equation with data in non standard spaces, Rend. Lincei Mat. Appl. 26 (2015), 241-262.

[18] C.G. Simader, On Dirichlet's boundary value problem, Lecture Note in Mathematics 268, Springer, 1972.

[19] G. Stampacchia, Equations elliptiques du second ordre à coefficients discontinus, Sem. Math. Super., Vol. 16, Les Presses de l'Universite de Montreal, 1966.

[20] G.N. Troianiello, Elliptic differential equations and obstacle problems, Plenum Press, 1987. 